\title{
Letters
}

\section{Adolescent development}

\section{Advice in $\mathrm{ABC}$ of adolescence is potentially misleading}

EDITOR-Christie and Viner say that delayed puberty in boys can be quite distressing but is almost always a normal variant. ${ }^{1}$ They say that boys aged 15 or over with a testicular volume of $4 \mathrm{ml}$ or more can be reassured that puberty is beginning and, by inference, do not require referral to a specialist. This advice is potentially misleading.

For all that it is a variant of normality, constitutional delay in growth and puberty can have adverse psychosocial and skeletal consequences. ${ }^{2-4}$ To deny an apubertal teenager the opportunity to choose low dose androgen treatment until he is into his 16th year would be unusual by present standards. Given the likely ensuing timescale, his doctor might as well refer him straight to an endocrinologist instead of a paediatrician.

A testicular volume of $4 \mathrm{ml}$ is well within the range found in boys with irreversible hypogonadotrophic hypogonadism and therefore by no means necessarily indicates that puberty is beginning. Many boys with hypogonadotrophic hypogonadism start puberty but fail to progress beyond the early stages. $^{5}$ Moreover, a history of cryptorchidism (especially if bilateral) or anosmia should prompt an even earlier referral. ${ }^{4}$ Neither does a family history of pubertal delay necessarily support a diagnosis of constitutional delay in growth and puberty, given the high prevalence of constitutional delay in growth and puberty among first degree relatives of patients with hypogonadotrophic hypogonadism.

A recurring theme in the personal stories posted on the www.Kallmanns.org website by men with irreversible hypogonadotrophic hypogonadism is of just how difficult it was for them as teenagers to screw up the courage to go to see their family doctor about a lack of secondary sexual characteristics. On being told "not to worry, because it's only pubertal delay," many felt (or were made to feel) so crushed and foolish that they then put off seeing a doctor until many years later.

Richard Quinton consultant endocrinologist Royal Victoria Infirmary, Newcastle on Tyne NE3 2NJ richard.quinton@nuth.nhs.uk

Competing interests: None declared.

1 Christie D, Viner R. ABC of adolescence: Adolescent development. BMJ 2005;330:301-4. (5 February.)
2 Skuse D. The psychological consequences of being small. $J$ Child Psychol Psychiat 1987;28:641-50.

3 Crowne EC, Shalet SM, Wallace WH, Eminson DM, Price DA. Final height in boys with untreated constitutional delay in growth and puberty. Arch Dis Child 1990;65:

4 Finkelstein JS, Klibanski A, Neer RM. A longitudinal evaluation of bone mineral density in adult men with historie of delayed puberty I Clin Endocrinol Metab 1996;81:

5 Quinton R, Duke VM, Robertson A, Kirk JMW, Matfin G, de Zoysa PA, et al. Idiopathic gonadotrophin deficiency: genetic questions addressed through phenotypic characerisation. Clin Endocrinol 2001:55:163-74.

\section{Author's reply}

EDITOR-Quinton acknowledges that apparent pubertal delay is a normal variant in most boys seen by general practitioners or by paediatric endocrinologists. However, he says that our advice, that boys aged 15 or over with a testicular volume of $4 \mathrm{ml}$ or more can be reassured that puberty is beginning, is potentially misleading, as $4 \mathrm{ml}$ testes are within the range found in adult men with the uncommon condition of irreversible hypogonadotrophic hypogonadism.

Our advice is appropriate for boys who present to general practitioners. The absence of any signs of puberty, or lack of further progression through puberty over the next six months should, of course, be viewed with suspicion and merit referral to a paediatric endocrinology service for full investigation, including consideration of conditions such as hypogonadotrophic hypogonadism.

Quinton thinks that even the normal variant of constitutional delay in growth and puberty can have adverse psychosocial consequences. ${ }^{1}$ However, newer larger studies have shown that boys who are small or whose adolescence is delayed are not psychologically disadvantaged. ${ }^{2}$ Rather than overtreating numbers of normal boys, we focus on improving the communication skills of general practitioners in discussing issues such as pubertal timing with young people.

Russell Viner consultant in adolescent medicine and endocrinology

University College London Hospitals NHS Foundation Trust and Great Ormond Street Hospital NHS Trust, London W1T 3AA rviner@ich.ucl.ac.uk

Competing interests: None declared.

1 Skuse D. The psychological consequences of being small.J Child Psychol Psychiatry 1987;28:641-50.

2 Sandberg DE, Bukowski WM, Fung CM, Noll RB. Height and social adjustment: are extremes a cause for concern and action? Pediatrics 2004;114:744-50.

\section{Cognitive behaviour therapy for adolescents with chronic fatigue syndrome}

\section{Data are insufficient and conclusion inappropriate}

EDITOR-I have concerns about the design and interpretation of the study reported by Stulemeijer et al on cognitive behaviour therapy for adolescents with chronic fatigue syndrome. ${ }^{1}$ The trial arms were not matched for the number of contacts with healthcare professionals. Experience from larger and more carefully controlled randomised interventional trials of patients with chronic fatigue syndrome has clearly shown that short term improvement in symptoms is related directly to the maintenance of regular contacts with healthcare professionals rather than the therapeutic effect of the intervention itself and consequently, the improvement is not sustained once the contact is lost. ${ }^{2}$

The authors did not offer patients in their waiting list the opportunity to meet therapists regularly for five months but without having cognitive behaviour therapy. Few follow up data on patients in the intervention arm show that the specific treatment benefit was carried forward without regular contacts with the therapists. A cautious approach is essential in inferring direct benefit from cognitive behaviour therapy in the intervention arm (as opposed to short term benefit from close contact with therapists). The level of activity in some of their participants whom the authors considered to be passive remained unclear.

In their summary points the authors claim that cognitive behaviour therapy was effective by challenging patients' belief that activity aggravated symptoms. Epidemiological data, however, confirm that fatigue made worse by exercise is a characteristic feature of adolescents at risk of chronic fatigue syndrome. ${ }^{3}$ Encouraging activity in disabled patients is entirely different from challenging an accepted feature of the disease. A rhetorical approach towards a physically and emotionally challenging condition does not help recovery and only encourages therapeutic failure.

Abhijit Chaudhuri senior lecturer in clinical neurosciences

University of Glasgow, Institute of Neurological Sciences, Glasgow G51 4TF ac54p@udcf.gla.ac.uk

Competing interests: None declared.

1 Stulemeijer M, de Jong LWAM, Fiselier TJW, Hoogveld SWB, Bleijenberg G. Cognitive behaviour therapy for adoescents with chronic fatigue syndrome: randomised controlled trial. BMJ 2005;330:14-8. (1 January.) 
2 Blacker CV, Greenwood DT, Wesnes KA, Wilson R, Woodward C, Howe I, et al. Effect of galantamine hydrobromide in chronic fatigue syndrome: a randomized controlled in chronic fatigue syndrome:
trial. JAMA 2004;292:1195-204. 3 Mears CJ, Taylor RR, Jordan KM, Binas HG. Sociodemoprimary care sample. J Adolesc Health 2004;35:528e.21-6.

\section{Authors' reply}

EDITOR-Chaudhuri's concerns relate to a possible placebo effect and the way we treat our patients. We consider it unlikely that the positive effects of our treatment are attributable mainly to non-specific treatment factors, since the results were maintained at eight month follow up even in the absence of contacts with the therapist (unpublished data). Moreover, others have shown that cognitive behaviour therapy was more effective than attention control conditions shortly after treatment and at long term follow-up. ${ }^{1-3}$

At the start of therapy all patients experienced severe limitations in performing activities appropriate to age. A characteristic belief of patients with chronic fatigue syndrome, especially in case of passive patients, is that fatigue is made worse by exercise. This cognition, although functional in the first phase of the condition, is dysfunctional in the longer term and maintains activity avoidance and symptoms. By challenging these and other activity related cognitions, activity regulation is possible. Thus, patients are taught to regulate and increase their physical and other activities in a systematic and safe way. Our results show that this is possible. The distinction between physically passive and relatively active patients, based on actometry, is helpful to select the correct approach to help the patient.

As in other chronic conditions, we do not have one treatment that leads to recovery in all patients. We believe that our study clearly shows that many of the participants benefited from cognitive behaviour therapy and were able to function as normal adolescents again.

Maja Stulemeijer junior researcher

Lieke W A M de Jong child psychologist

Theo J W Fiselier paediatrician

Sigrid W B Hoogveld junior researcher

Gijs Bleijenberg professor

G.Bleijenberg@nkcv.umcn.nl

Radboud University Nijmegen Medical Centre,

Expert Centre Chronic Fatigue, PO Box 9101, 6500 HB Nijmegen, Netherlands

Competing interests: None declared.

1 Prins JB, Bleijenberg G, Bazelmans E, Elving LD, de Boo Th, Severens JL, et al. Cognitive behaviour therapy for chronic fatigue syndrome: a multicentre randomised controlled trial. Lancet 2001;357:841-7.

2 Deale A, Chalder T, Marks I, Wessely S. Cognitive behavior therapy for chronic fatigue syndrome: a randomized controlled trial. Am J Psychiatry 1997;154:408-14.

3 Deale A, Husain K, Chalder T, Wessely S. Long term outcome of cognitive behavior therapy versus relaxation therapy for chronic fatigue syndrome: a 5-year follow-up study. Am J Psychiatry 2001;158:2038-42.

\section{How to prevent caesarean deliveries deserves more study}

EDITOR-Declercq et al bring to light "no indicated risk" as a new classification of caesarean delivery. ${ }^{1}$ Like other classes of caesarean delivery, annual rates of caesarean sections with no indicated risk have been increasing in the United States and around the world. In the context of these increases, we are surprised that methods of care that might prevent caesarean delivery have not been pursued more aggressively.

Caesarean delivery is strongly correlated to the age of the mother, parity, and increasing gestational age within the term period of pregnancy. $^{12}$ If caesarean delivery is an adverse outcome worthy of prevention, if risk factors for caesarean delivery can be identified, and if a latent period exists between the identification of risk and the development of situations requiring caesarean delivery then perhaps a preventive approach-encouraging patients with risk factors to enter labour before their risk can become disease-could lower caesarean delivery rates safely.

Our working group recently described the use of risk driven, prostaglandin assisted induction of labour, and this intervention was associated with a rate of caesarean delivery of only 4\%. ${ }^{3}$ While Declercq et al think that research should be done to elucidate whether the risks of primary caesarean delivery in cases of no indicated risk will be offset by associated benefits, we hope that an equal amount of time and effort will be spent on developing and testing methods that might safely prevent, or lower, rates of caesarean delivery performed for this and the other more traditional indications.

\section{James M Nicholson assistant professor} james.nicholson@uphs.upenn.edu

Lisa C Kellar first year fellow

Peter F Cronholm clinical instructor

Department of Family Practice and Community

Medicine, 2 Gates, Hospital of the University of

Pennsylvania, 3400 Spruce Street, Philadelphia, PA

19104, USA

Competing interests: None declared.

1 Declercq E, Menacker F, MacDorman. Rise in "no indicated risk" primary caesareans in the United State 1991-2001: cross sectional analysis. BMJ 2005;330:71-2. (8 January.)

2 Caughey AB, Musci TJ. Complications of term pregnancies beyond 37 weeks of gestation. Obstet Gynecol 2004;103:57-62.

3 Nicholson JM, Kellar LC, Cronholm PF, Macones GA Active management of risk in pregnancy at term: an association between a higher induction of labor rate and a lower cesarean delivery rate. Am J Obstet Gynecol 2004;191:1516-28.

\section{Early epidurals increase caesarean rate, meta-analysis shows}

EDITOR-The study reported by Mayor in her news item uses the term "neuraxial analgesia" and claims that early epidurals do not increase the rate of caesarean deliveries. ${ }^{12}$ This is confusing as the study was not of early epidural analgesia, and the oxytocin augmentation rate of $75 \%$ at first analgesia makes for lack of generalisability.

The claim that women need not worry that early epidurals will lead to increased caesareans is false. ${ }^{3}$ This trial was about two methods of helping women with pain in early labour. In the so called epidural arm, on their first request for analgesia, women received intrathecal fentanyl, and in the narcotic arm, hydromorphone. On their second request, almost two thirds of women in both arms were $4 \mathrm{~cm}$ or more dilated. In the intrathecal "epidural" arm, they received low dose epidurals; in the narcotic arm, hydromophone.

This trial, as others that have contributed to the Cochrane meta-analysis, ${ }^{45}$ showed no increase in caesareans in the presence of epidural analgesia, but does not acknowledge that most women were in active labour at randomisation, when most will do well. Wong et al, ${ }^{2}$ like Sharma et al, the major contributors to the Cochrane meta-analysis, have shown only that when women's pain in the latent phase is managed with intrathecal, narcotic, or other pharmacological or non-pharmacological means, an epidural in the active phase of labour does not increase the rate of caesareans.

The role of an early epidural in contributing to increases in caesarean rates has yet to be studied in an randomised controlled trials, but the sensitivity analysis in the Cochrane meta-analysis, after removing late randomisation studies, shows that early epidurals to more than double caesarean rates.

Michael C Klein physician

BC Women's Hospital, Vancouver, British

Columbia, Canada V6H 3VJ

mklein@interchange.ubc.ca

Competing interests: None declared.

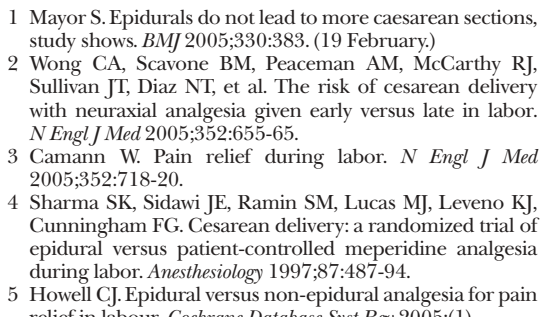

relief in labour. Cochrane Database Syst Rev 2005;(1).

\section{Clomipramine and neuroleptic malignant syndrome}

\section{Literature on adverse reactions to} psychotropic drugs continues to confuse

EDITOR-Haddow et al describe a severe adverse drug reaction but create an oxymoron in describing clomipramine induced "neuroleptic malignant syndrome."1

Clomipramine is not a neuroleptic and therefore by definition cannot cause this syndrome (any more than it can cause anticonvulsant hypersensitivity syndrome). The description is consistent with serotonin toxicity, a well described adverse reaction to serotonergic antidepressants. In attempting to describe a new adverse drug reaction, Haddow et al have focused on non-specific clinical features that are present in many drug induced neuropsychiatric syndromes. ${ }^{2}$ Clomipramine, a potent serotonin reuptake inhibitor, has been associated with hyperthermia and was more correctly labelled as serotonin toxicity. $^{3}{ }^{4}$ Muscle rigidity and raised muscle enzyme activities also occur in severe serotonin toxicity.

Neuroleptic malignant syndrome is an idiosyncratic reaction to therapeutic doses of neuroleptic agents. ${ }^{5}$ A pragmatic clinical 
description of the syndrome includes four primary features: autonomic lability, hyperthermia (pyrexia) without other cause, extrapyramidal syndrome (cog-wheel or lead pipe rigidity), and encephalopathy. Despite superficial clinical similarities between neuroleptic malignant syndrome and serotonin syndrome, they are usually easily differentiated on the basis of careful neurological examination. Neuroleptic malignant syndrome is associated with lead pipe rigidity, bradykinesia, and other extrapyramidal features. ${ }^{5}$ Conversely in serotonin syndrome there is hyperkinesia, hyperreflexia, and clonus. ${ }^{45}$

Descriptions of adverse reactions to psychotropic drugs need detailed clinical descriptions of neuromuscular, central, and autonomic features. Using ambiguous or non-specific criteria to label adverse reactions as a particular syndrome while ignoring the pharmacology of the implicated drug may lead to false associations between particular drugs and clinical syndromes and to inappropriate treatment.

Geoffrey K Isbister clinical toxicologist

Newcastle Mater Misericordiae Hospital, Edith

Street, Waratah, NSW 2298, Australia

gsbite@ferntree.com

Nicholas A Buckley associate professor

Clinical Pharmacology and Toxicology, Canberra

Hospital, PO Box 11, Woden, ACT 2606, Australia

Competing interests: None declared.

1 Haddow AM, Harris D, Wilson M, Logie H. Clomipramine induced neuroleptic malignant syndrome and pyrexia of induced neuroleptic malignant syndrome and pyre
unknown origin. BMJ 2004;329:1333-5. (4 December.)

2 Unknown origin. BMJ 2004;329:1333-5. (4 December.) 2 Velamoor VR. Neuroleptic malignant syndrome. Recogni-
tion, prevention and management. Drug Saf 1998;19:73-82. 3 Neuvonen PJ, Pohjola-Sintonen S, Tacke U, Vuori E. Five Neuvonen PJ, Pohjola-Sintonen S, Tacke U, Vuori E. Five
fatal cases of serotonin syndrome after moclobemidefatal cases of serotonin syndrome after moclobemide-
citalopram or moclobemide-clomipramine overdoses. citalopram or mocl

4 Dunkley EJ, Isbister GK, Sibbritt D, Dawson AH, Whyte IM. The Hunter Serotonin Toxicity Criteria: simple and accurate diagnostic decision rules for serotonin toxicity. $Q$ accurate diagnostic decic

5 Gillman PK. The serotonin syndrome and its treatment.

Psychopharmacol 1999;13:100-9.

\section{Authors' reply}

EDITOR-Clomipramine is not a neuroleptic and is classed as an "antidepressant." However, as mentioned in our article, this drug has an appreciable blocking effect at dopamine receptor sites, the traditional domain of the neuroleptic drug. This is a weak effect, but it is more potent than several other antidepressant agents. ${ }^{1}$ This action is recognised in the current edition of the $B N F$, which says that neuroleptic malignant syndrome may, very rarely, arise in the course of antidepressant treatment. ${ }^{2}$

We also made reference to 50 worldwide reports received regarding clomipramine and neuroleptic malignant syndrome or suspected neuroleptic malignant syndrome, in addition to four reports received by the Committee on Safety of Medicines and two published case reports.

We agree that we should have made clear that this patient's muscle rigidity was of the lead pipe variety, although some widely accepted diagnostic criteria require only severe muscle rigidity. ${ }^{3}$ The diagnostic criteria that we tabulated were based on
Levinson and Sternabach and referenced in our article. ${ }^{4}$

We described in this patient an earlier diagnosed episode of serotonin syndrome, and no clinical evidence of rigidity was found on that occasion.

In view of the action at dopamine sites of clomipramine, and the statement in the $B N F$ from the BMA and the Royal Pharmaceutical Society of Great Britain, we would continue to support our diagnosis of neuroleptic malignant syndrome in this informative case.

Alison Haddow consultant in old age psychiatry Royal Cornhill Hospital, Aberdeen AB25 2ZH alison.haddow@gpct.Grampian.scot.nhs.uk

Martin Wilson clinical lecturer

Department of Medicine for the Elderly, University of Aberdeen, Aberdeen AB25 2ZD

\section{Competing interests: None declared.}

1 Tatsumi M, Groshan K, Blakely R, Richelso E. Pharmacological profile of antidepressant and related compounds at logical profile of antidepressant and related compounds at 340:249-58

2 Diagnostic and statistical manual for mental disorders, fourth edition (DSM-IV). Washington DC: American Psychiatric Press, 1994:739-49.

3 British Medical Association, Royal Pharmaceutical Society of Great Britain. British national formulary 2004;48: of Great Br

Levenson JL. Neuroleptic malignant syndrome. Am J Psehiary 1985;142:1137-45

Sternabach H. The serotonin syndrome. Am J Psychiatr $1991 ; 148: 705-13$.

\section{Risks of gene therapy should be weighed against lack of alternatives for many diseases}

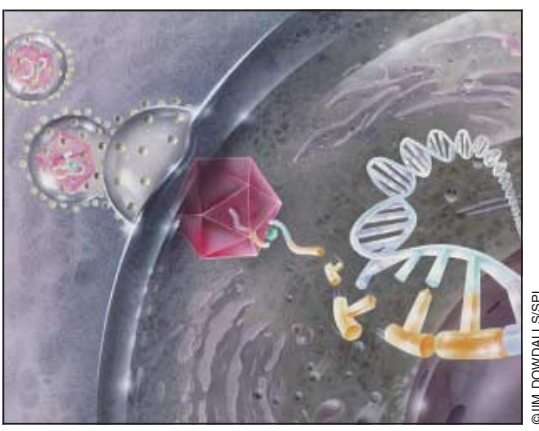

Artwork of gene therapy

EDITOR-Kimmelman provided a comprehensive discussion about the risks and ethics of gene therapy. ${ }^{1}$ We certainly cannot predict the future, but the risks should be weighed against the complete lack of alternative options for many of the diseases discussed.

The two cases of T cell leukaemia in the $\mathrm{X}$ linked severe combined immunodeficiency gene therapy trial are presented as typical examples of malignant transformation. However, that treatment entailed the modification of immature stem cells, which may present additional risks. ${ }^{2}$ Much work is being done in vector design to lessen these risks. Relative risks and toxicities are also likely to be linked to the disease type and target cell. For non-lethal disorders such as the inherited retinal dystrophies, minimising risk is of even more importance. However, gene transfer to a post-mitotic cell such as a photoreceptor by using a vector with limited genomic integra- tion, such as recombinant adeno-associated virus, is much less likely to be mutagenic.

The risks of gene therapy must be weighed carefully against the risks and efficacy of existing treatment. Conventional treatments such as organ transplantation, which are no longer considered experimental, are associated with substantial morbidity and mortality. ${ }^{3}$ The difficult balance is to steer a path between the ethical application of new untested strategies with the potential to improve health care, and a position of caution. As with conventional medicines, the risks and ethics of gene therapy should probably be reflected in this light.

Robert E MacLaren $M R C$ research fellow

Robin R Ali professor of human molecular genetics Division of Molecular Therapy, Institute of Ophthalmology, University College London, London EC1V 9EI

Adrian J Thrasher professor of paediatric immunology

Molecular Immunology Unit, Institute of Child Health, UCL, London WC1N 1EH

Competing interests: None declared.

1 Kimmelman J. Recent developments in gene transfer: risks and ethics. BMJ 2005;330:79-82. (8 January.)

2 McCormack MP, Rabbitts TH. Activation of the T-cell oncogene LMO2 after gene therapy for X-linked severe combined immunodeficiency. $N$ Engl J Med 2004.350: 913-22.

Newstead CG. Assessment of risk of cancer after renal transplantation. Lancet 1998;351:623-8.

\section{Need for expertise based randomised controlled trials}

\section{Expertise based design has shortfalls}

EDITOR-Devereaux et al discussed the need for expertise based randomised controlled trials for surgical procedures. ${ }^{1}$

Firstly, the use of expertise based designs does not necessarily enhance the validity of a surgical trial. Surgical outcome does not depend solely on the operation; other factors that influence the results of an operation are heterogeneous and immeasurable (postoperative management, the surgical team, equipment). A different bias is introduced by the expertise based design, the influence of the overall performance of surgeon $\mathrm{A} v \mathrm{~B}$, and in this regard, expertise based design is not necessarily a more valid comparison of operation A $v \mathrm{~B}$.

Secondly, the use of expertise based designs does not necessarily enhance the applicability of a surgical trial. The expertise based design assumes that an operation will only be performed by a select few. This is rarely the case, and hence the results will not reflect the true performance of an operation introduced to the general public (performed by a variety of surgeons).

Moreover, the results of expertise based design trials do not take into account any learning curve that exists when a new operation is introduced. The initial rates of adverse outcomes are higher when a surgeon refines an existing operative technique, ${ }^{2}$ never mind a new one.

A solution is to perform a randomised trial that has a balanced surgical expertise in 
both arms in proportions reflective of the population that will perform the operations. Academics can analyse the "expertise" subgroup, while the rest of us can look at the overall results to determine how an operation will really perform.

Eric Lim specialist registrar

Papworth Hospital, Papworth Everard, Cambridge CB3 8RE

eric.lim@cvsnet.org

Competing interests: None declared.

Devereaux PJ, Bhandari M, Clarke M, Montori VM, Cook DJ, Yusuf S, et al. Need for expertise based randomised DJ, Yusuf S, et al. Need for expertise based 1

2 Bridgewater B, Grayson AD, Au J, Hassan R, Dihmis WC, Munsch C, Waterworth P. Improving mortality of coronary Munsch C, Waterworth P. Improving mortality of coronary
surgery over first four years of independent practice: retrosurgery over first four years of independent practice: retro-
spective examination of prospectively collected data from 15 surgeons. BMJ 2004;329:421.

\section{Surgical research shares many} similarities with psychotherapy research

EDITOR-Of course the expertise based randomised trial, mooted for surgical procedures by Devereaux et $\mathrm{al}^{1}{ }^{1}$ is the norm in psychotherapy research when comparing two different psychotherapies. A similar debate on the interpretation of such trials occurred in the psychotherapy literature.

Research in surgery and psychotherapy share other similarities beyond having to account for practitioner expertise. There is the issue of blindness-hard to achieve for both patient and doctor in these disciplines-as well as the "why test it, it's obvious it makes a difference" argument. Both disciplines could learn from each other about the design and analysis of clinical research.

Simon Hatcher senior lecturer in psychiatry Department of Psychological Medicine, Faculty of Medical and Health Sciences, University of Auckland, Private Bag 92019, Auckland 1, New Zealand

s.hatcher@auckland.ac.nz

Competing interests: None declared.

Devereaux PJ, Bhandari M, Clarke M, Montori VM, Cook DJ, Yusuf S, et al. Need for expertise based randomised controlled trials. BMJ 2005;330:88. (8 January)

2 Barber JP, Foltz C, Crits-Christoph P, Chittams J. Therapists' adherence and competence and treatment discrimination in the NIDA collaborative cocaine treatment study.J Clin Psychol 2004;60:29-41.

\section{Target SHOs and registrars for communication skills training}

EDITOR-Kidd et al argue that undergraduates need to learn clinical and communication skills side by side. ${ }^{1}$ Every doctor needs communication skills, from pathologists to surgeons and physicians. In the Netherlands undergraduates spend considerable time on how to communicate with patients. But I think that this is targeting the wrong group, and time is taken away from essential preclinical and clinical studies. Students learn to talk to simulated patients with, for example, a Dukes's D colon cancer, at a time in their studies when they don't know what cancer is, what a Dukes's D colon cancer means, and what the impact is on a patient. Students receive this kind of training in their second year and have forgotten about it when they become senior house officers.
Senior house officers (SHOs) and registrars should be doing the training. We do the damage in our "bad news" talks. We know what we are talking about, and we do it daily. We should be the ones filmed on camera and evaluated. This should be done with clinicians with experience, together with "communicators," and not only by people who studied communication skills who have never had to tell anybody that they have cancer and are dying, or let a family know that a patient has died. The impact of this is greater than most people can imagine, and I think poor communication on those subjects often reflects the inability of the doctor to deal with his or her own feelings.

The same goes for communicating with colleagues. In my hospital, emergency departments are now filmed in major trauma cases, and the people on the floor are actually the ones being filmed. Evaluation is then done by the surgeons, together with a psychologist.

Communication skills are essential, but not at the expense of medical students' preclinical and clinical curriculum. The target groups should therefore be senior house officers and specialist registrars.

Erik $\mathbf{T}$ Walbeehm specialist registrar plastic surgery Rotterdam, 3022 BC, Netherlands erikwalbeehm@mac.com

\section{Competing interests: None declared.}

1 Kidd J, Patel V, Peile E, Carter Y. Clinical and communication skills. BMJ 2005;330:374-5. (19 February.)

\section{Old docs and new tricks}

\section{Seasoned doctors may be better than} young doctors at some things

EDITOR-Spurgeon reports that the doctors' standards of care drop with years in practice. ${ }^{1}$ When I began clinical practice in the late 1980 s I thought that one key to being a "good doc" was keeping up with the latest drugs and technologies. I was dismayed to see seasoned colleagues who were slow to change.

I then saw many new drugs get pulled from the market (rofecoxib is not the first non-steroidal anti-inflammatory drug to be withdrawn) and various medical fads come and go. Evidence based medicine appropriately shed light on the poor evidence available to support most things that physicians do.

Armed with this keener analytical approach, I came to realise that most claims of benefit are greatly exaggerated compared with absolute incremental changes and that most patients are not like trial subjects. Although an intervention might benefit a population, it is much less certain that it will benefit the patient who sits before me.

I suspect that seasoned doctors are better than their junior colleagues at some things, and worse at others. Maybe the ability to see the big picture, diagnostically and therapeutically, is enhanced by experience. Meanwhile the emphasis on the newest treatment detail might wane. Perhaps that is a reason why I have conflicting opinions about whether doctors get better with time. Louis B Jacques physician 918 Barracuda Cove Court, Annapolis, MD 21401, USA

JacquesL@georgetown.edu

Competing interests: None declared.

1 Spurgeon D. Standard of care by doctors may drop with years spent in practice. BMJ 2005;330:384-a. (19 February.)

\section{Efficiency is important}

EDITOR-In British general practice, where everyday demand exceeds capacity, the efficient general practitioner is king. That is one thing that experience should bring. If all general practitioners followed every guideline the system would collapse, and although a few patients would have exemplary care, many would have no care at all as they would just not get seen because they would find the wait intolerable. Perhaps this is what happens now in secondary care, where care delivered is often very good but access is less and less.

Accepted practice is often developed for a "one issue patient." Reality means multiissue patients, who themselves have limited ability to follow all the investigation and "treatment" recommended by the single issue academic establishment. Many indications for treatment are immediately met with contraindications. Experience allows general practitioners to cut back on too much excess investigation and treatment while still striving to meet the guidelines.

Protecting the patient from the iatrogenic harm of excess health care used to be a core skill of the general practitioner. Is this being taken away from us as well?

A system that fails to value the soft end points and often efficient and effective care that experience brings will have to restructure to meet the demand and that inevitably will lead to a hugely expanded system with resource implications. I am not disputing the findings of the paper reported by Spurgeon, that the standard of care may drop with years spent in practice, ${ }^{1}$ but the immediate common sense illogically of its hypothesis and conclusions make me advise to proceed down this route with caution. Being a doctor is already a difficult job. Being advised that all your thoughtful patient experience has actually made you a worse doctor is demotivating. Perhaps experienced doctors and patients would have a different set of criteria about what good care is?

Graeme M Mackenzie general practitioner Whitehaven CA28 7RG

graeme.mackenzie@gp-a82041.nhs.uk

Competing interests: None declared.

1 Spurgeon D. Standard of care by doctors may drop with years spent in practice. BMJ 2005;330:384-a. (19 February)

\section{bimj.com}

Letters appearing here are an edited selection of rapid responses originally posted on bmi.com

We ask for all letters to the editor to be submitted as rapid responses via bmj.com

For advice see: bmj.com/rapidresponses 